\title{
A New Test of Filterability for Unprocessed Wines Evaluation of the Enzyme Efficiency
}

\author{
Amélie Vallet-Courbin ${ }^{1}$, Soizic Lacampagne ${ }^{1}$, Rose Marie Canal-Llauberes ${ }^{2,3}$, Sigolène \\ Mattalana Malzieu ${ }^{1,2}$, Tihomir Kanev ${ }^{1,2}$, Martine Mietton-Peuchot ${ }^{1}$, Rémy Ghidossi ${ }^{1 *}$ \\ 1. Unité de recherche Enologie EA 4577, USC 1366 INRA, Bordeaux INP, 210, chemin de Leysotte - CS 50008 \\ 33882 Villenave d'Ornon cedex, France \\ 2. Novozymes, Cité Mondiale, 23 Parvis des Chartrons, 33074 Bordeaux Cedex, France \\ 3. RCL-BIOPROCESS, 51 rue Lagrange, 33000 Bordeaux, France \\ E-mail: remy.ghidossi@u-bordeaux.fr (*Corresponding author)
}

Received: 4 November 2021; Accepted: 2 December 2021; Available online: 15 December 2021

\begin{abstract}
A new Test of Filterability has been developed. Measurements carried out with different types of wines indicate that the new filterability index is a useful tool for understanding and predicting the propensity to fouling of treated or untreated wines, e.g. with or without enzyme addition. The measurement method used in the Test of Filterability, requires only one type of membrane for all types of wine, and uses the same equipment as the traditional Fouling Index. Numerous trials have demonstrated that the filtration of wines is governed by standard blocking law. The definition of the new Test of Filterability, based on this filtration law, is proposed. The choice of membrane and the selection of the optimal pore size were based on the results of the experiments. Current methods used for the determination of fouling properties in wine filtration have been developed for the membrane filtration of small quantities of suspended matter. Enzyme treatment is a process often used in wine clarification. The new Test of Filterability indicates the best conditions for the filtration of all types of wines. The test is easy to implement and has been validated with various wines. This new Test of Filterability is an important tool for winemakers as it constitutes a simplified test of a wine's filterability. The new test may also be used to determine the filtration process that is best adapted to each wine while reducing the number of operations. The same approach may be adopted for the filtration of other liquids.
\end{abstract}

Keywords: Test of filterability; Fouling; Wine; Pectinases; Glucanases; Enzymes.

\section{Introduction}

Filtration can occur at several stages of the production of both red and white wines. It can take place prior to clarification, after treatments such as fining, or also prior to bottling depending on the effect desired by the winemaker. Filtration in winemaking is used to attain two main objectives: clarification and/or microbial stabilization [1]. In clarification, large particles that affect the visual appearance of the wine are removed. In microbial stabilization, bacteria or yeasts are removed, thereby reducing the probability of re-fermentation or spoilage. The process of clarification involves the removal of particles from, in general, 1 to $10 \mu \mathrm{m}$ and microbial stabilization requires a filtration less than $0.65 \mu \mathrm{m}$. Filtration is the technique usually used for wine clarification or to remove micro-organisms with a wide range of concentrations: from $1 \mathrm{mg} . \mathrm{L}^{-1}$ to $400 \mathrm{~g}$.. $\mathrm{L}^{-1}$ [2-6]. Limpidity and microbiological stability are two essential parameters which may affect the organoleptic properties of a wine. Compounds removed by filtration can be classed in three groups according to their size: solutes $(<1 \mathrm{~nm})$, colloids (between $1 \mathrm{~nm}$ and $1 \mu \mathrm{m}$ ), and particles $(>1 \mu \mathrm{m})$ [7]. Winemakers strive to choose the filtration technique best adapted to their objectives in terms of wine characteristics. Two main technologies are used: precoat or membrane filtration. Different designs of filtration equipment are available: drum filters, plate and frame filters, press filters, cartridges or cross-flow filters. The filtration process must be efficient in terms of retention and produce adequate flow-rates without prejudice to the quality of the wine. These criteria can be difficult to reconcile due to fouling of the filtering equipment over time. Fouling modifies both the flow-rate and the retention characteristics of filters [8].

In order to prevent the filtration process from coming to a rapid halt due to fouling, it is necessary to choose the right type of filtration (technology, type of media, and pore size) and to define the ability of wine to filter. A filtration time of 8 hours with the filtrate flux maintained at the predicted flow-rate as given by the manufacturer might be considered as a well-adapted set-up. Parameters such as turbidity, the fouling index (FI), maximum 
filterable volume (Vmax) and/or microorganism identification and quantification are habitually used in determining the best filtration configuration. Turbidity is caused by the formation of light-scattering complexes induced by the colloids and small particles present in wine. Colloidal content in wine contributes to wine turbidity and can play a significant role in fouling [9-14]. However, the measurement of turbidity alone is not sufficient for a reliable estimation of the filterability of a wine. A wine of relatively low turbidity can clog filters very quickly due to a high micro-organisms content (Garza and Boulton, 1984) or due to the presence of pectins and glucans.

In the cellar $\mathrm{V}_{\max }$ and FI are usually determined following the measurement of turbidity. These indices are determined by a dead-end filtration under constant pressure, using a 25mm-diameter cellulose ester Millipore membrane with a pore diameter of $0.65 \mu \mathrm{m} . \mathrm{V}_{\max }(1)$ is calculated using the equation for the linearized form of standard blocking law at constant pressure (Gaillard, 1976).

$$
\begin{aligned}
& V_{\max }=\frac{t_{2}-t_{1}}{\frac{t_{2}}{V_{2}}-\frac{t_{1}}{V_{1}}} \\
& \frac{t}{V}=K t+\frac{1}{q_{0}}
\end{aligned}
$$

At a pressure of 1 bar, the volumes filtered $V_{1}$ and $V_{2}$ after respectively $2\left(t_{1}\right)$ and $5\left(t_{2}\right)$ minutes were measured. $V_{\max }$ represents the inverse of the slope of the line $t / V=f(t)$ between $t_{2}=5$ min and $t_{1}=2$ min. The value of $V_{\max }$ indicates whether the wine is filterable on membranes and this index can be used to estimate the maximum volume filterable through a $0.65 \mu \mathrm{m}$ filter before fouling occurs. Experiments have shown that in order to obtain a satisfactory flow-rate, the $\mathrm{V}_{\max }$ must be above $4000 \mathrm{~mL}$ [15]. When the value is less than $4000 \mathrm{~mL}$, membrane filtration is not recommended because a wine giving such a value would cause rapid blockage of the filter pores. The FI is determined using the same membrane and the same apparatus as for $V_{\max }$. It is calculated (3) from the time (ms) it takes to filter $200 \mathrm{~mL}$ and $400 \mathrm{~mL}$ of wine under a constant pressure of 2 bars. The interpretation of FI depends on the resulting values; for an index below 20, membrane filtration is feasible. In other cases, FI interpretation is not possible. Sometimes the flow-rate is so low that it is not possible to determine FI. This index was introduced in oenology in order to aid in the preparation of wines prior to membrane filtration. $V_{\max }$ and FI are especially well adapted to wines that have been pre-filtered and which are ready to undergo a final clarification prior to bottling. These indices are not suited to the qualification of the filterability of all wines, especially of unprocessed wines. In cases where it is not possible to interpret readings, no other indications are available to the winemaker. CFLA (Lamothe-Abiet Filtration Criteria) has recently been developed with a view to evaluating the filterability of such wines [16-18]. This method, now employed in oenology laboratories, involves the use of different membranes adapted to the initial wine.

The objective of this study is to present a new easy-to-use test named "Test of Filterability" suited to the qualification of a wide range of wines from unprocessed wine to wine ready for bottling. Many studies have shown the impact of enzyme preparation on the clarification and filterability of wine [19-23]. These enzyme preparations contain pectinases or beta-glucanases ( $\beta 1-3, \beta$ 1-6) which hydrolyze pectins and glucans in wine [24]. Enzyme preparations are recommended for wines which have a high propensity to clog filters. Nevertheless, the impact of such enzyme preparation on wine filterability is not always demonstrated by the established indices ( $\mathrm{V}_{\max }$ and FI) as they are not adapted to unprocessed wines. However, on an industrial scale, the assessment of improvements achieved by enzyme treatment is a key parameter prior to filtering the wine. In this study the Test of Filterability (TF) was performed on wine both treated and untreated by enzyme preparation in order to highlight the relevance of this new tool.

\section{Materials and methods}

\subsection{Wine type and origins}

The origins of the wines used in this study are listed below (Table 1). Wines $\mathrm{G}$ and $\mathrm{H}$ come from the same production site, wine $\mathrm{G}$ was aged in tank and wine $\mathrm{H}$ was aged in barrel.

\subsection{Oenological analysis}

Wines were qualified at the outset by measuring the standard oenological parameters: $\mathrm{pH}$, turbidity, alcoholic strength, titrable acidity, and volatile acidity. The alcoholic strength was measured after distillation by vapour formation using an electronic densimeter (Anton-Parr DMA $35 \mathrm{~N}$ ). Wine $\mathrm{pH}$ was measured with a $\mathrm{pH}-\mathrm{meter}(\mathrm{pH}$ 538 Multical WTW) standardized to $\mathrm{pH} 7.0$ and 4.0. Free $\mathrm{SO}_{2}$ was determined by the Ripper method [25]. Turbidity measurements of the wine samples were carried out by means of a Hach turbidimeter (Hach 2100 Q). The chromatic characteristics were analyzed with a double beam spectrophotometer (Jasco V550). Colour intensity (CI) and modified colour intensity (MCI) were determined by measuring absorbency at 420, 520, and $620 \mathrm{~nm}$ in a $1 \mathrm{~mm}$ cell. $\mathrm{CI}$ is determined by calculating $\mathrm{CI}=A 420+A 520$ and $\mathrm{MCI}$ by calculating $\mathrm{MCI}=A 420+A 520+$ 
A620. The hue is obtained by calculating $\mathrm{H}=A 420 / A 520$. The total phenols index (TPI) is determined using a wine sample diluted (x100) in a $10 \mathrm{~mm}$ quartz cell and measured at $280 \mathrm{~nm}$.

Table 1. Origin of wines

\begin{tabular}{ccl}
\hline Wine & Type & \multicolumn{1}{c}{ Origin } \\
\hline A & red wine & Bordeaux (Quinsac) \\
B & red wine & Bordeaux (Graves de Vayres) \\
C & red wine & Bordeaux (Romagne) \\
D & rosé wine & Languedoc (Vin de pays Val de Montferand) \\
E & red wine & Bordeaux \\
F & red wine & Bordeaux \\
H and G & red wine & Bordeaux (Haut-Medoc) \\
I & red wine & Bordeaux \\
J & red wine & Bordeaux (Quinsac) \\
\hline
\end{tabular}

\subsection{Membranes}

During development of the filterability test, several types of membranes of different composition and pore size were tested (Table 2).

Table 2. Membrane characteristics

\begin{tabular}{ccc}
\hline Composition & Manufacturer & Pore diameter $(\boldsymbol{\mu m})$ \\
\hline Cellulose ester (CE) & Millipore & 0.65 \\
\hline & & 0.20 \\
& & 0.30 \\
Cellulose nitrate (CN) & Sartorius & 0.45 \\
& & 0.65 \\
& & 0.80 \\
& & 1.20 \\
& & 3 \\
& & 5 \\
\hline Regenerate Cellulose (RC) & Schleicher \& Schuell & 8 \\
\hline Cellulose acetate (CA) & Sartorius & 0.60 \\
\hline Polytetrafluorethylene (PTFE) & Vladipor & 0.65 \\
\hline Glass fibre (GF) & Whatman & 0.60 \\
\hline
\end{tabular}

\subsection{Enzymes treatment}

Enzyme treatment was used to increase the filterability of the wines. In this way, wine properties were modified in order to better apprehend the precision of the new Test of Filterability and to demonstrate the effectiveness of the enzymes. Vinoflow $\mathrm{G}$ (Novozymes) is a mixture of two active elements: a pectinase and a glucanase ( $\beta 1-3,1-$ 6). Vinoflow $G$ enzyme improves filterability, clarification and, in turn, the quality of wine. This preparation acts on fouling substances that are hydrolyzed into smaller molecules thereby enhancing the precipitation of colloids. After racking, the filterability of wine is improved and throughout the filtration process medium fouling is reduced. The enzyme is supplied in the form of powder the dosage of which is $50 \mathrm{mg} . \mathrm{L}^{-1}$ for red wines. The enzyme needs to be dissolved in water before being incorporated into the wine. Wines are treated at $10^{\circ} \mathrm{C}$ for 5 days.

\subsection{Qualification of filterability} equation:

The Fouling Index (FI) is measured according to the Laurenty method [26] and is calculated using the

$$
\mathrm{FI}=\left(\mathrm{T}_{400}-2 \mathrm{~T}_{200}\right) \times 10 / 6
$$

where $\mathrm{T}_{200}$ and $\mathrm{T}_{400}$ are the times taken to filter $200 \mathrm{~mL}$ then $400 \mathrm{~mL}$ of a sample at 2 bars on a Millipore membrane (diameter $2.5 \mathrm{~cm}$, area $3.9 \mathrm{~cm}^{2}$, and nominal pore size $0.65 \mu \mathrm{m}$ ) in a continuous measurement. If $\mathrm{T}_{400}$ exceeds five minutes it is not possible to calculate FI and the volume filtered in five minutes is used.

The aim of this study is to define the Test of Filterability (TF). The development and the measurement protocols are detailed below. During the test, the volume filtered is measured as a function of time (timed intervals 10sec) 
using scales (Mettler Toledo, PM 4000) and data are collected with the program "Balance Link" developed by Mettler Toledo.

\subsection{Statistical analysis}

Each experiment was repeated at least three times. Mean and standard deviations of the data were calculated.

\section{Results and discussion}

\subsection{Limitations of the Fouling Index for the qualification of wine filterability}

In the wine industry the filterability of wine is usually determined by means of the Fouling Index (FI) prior to the final filtration and bottling. In order to improve the efficiency of the filtration process, wines can be treated with enzyme preparations which degrade polysaccharides. To illustrate the limitations of FI, measurements were carried out on two samples of a red wine from the Bordeaux area, one treated and the other untreated with the enzyme preparation. The results obtained for FI are shown in Figure 1. Table 3 provides the standard analytical parameters of the wine.

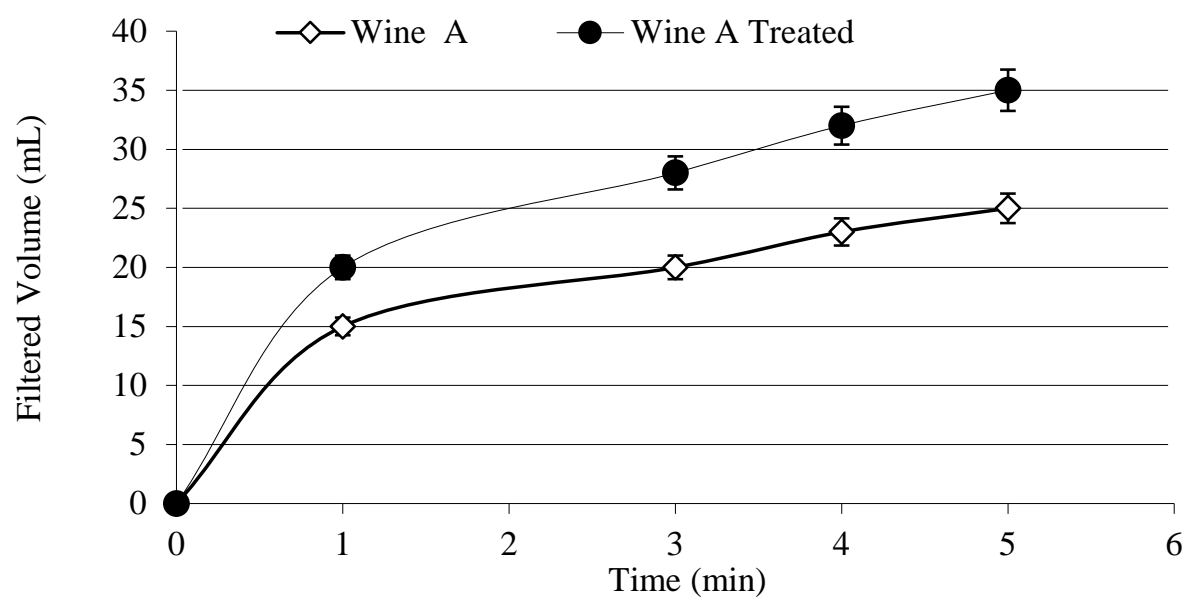

Figure 1. Filterability of the treated wine $(\bullet)$ and not treated wine $(\diamond)$

Table 3. Standard analytical parameters of Wine A

\begin{tabular}{lcc}
\hline Analytical parameters & \multicolumn{2}{c}{ Wine A } \\
& Control & Treated \\
\hline Alcoholic strength (\% v/v) & 12.5 & 12.5 \\
Turbidity (NTU) & 43 & 19 \\
pH & 3.6 & 3.6 \\
Free SO $(\mathrm{mg} / \mathrm{L})$ & 12.8 & 12.8 \\
Titrable acidity (mg tartaric acid/L) & 5.1 & 4.5 \\
Volatile acidity (mg acetic acid/L) & 0.45 & 0.45 \\
OD 420 nm & 0.27 & 0.26 \\
OD 520 nm & 0.33 & 0.33 \\
OD 620 nm & 0.009 & 0.008 \\
Colour intensity & 0.60 & 0.59 \\
Modified Colour intensity & 0.69 & 0.67 \\
Hue & 0.82 & 0.79 \\
PTI & 48.6 & 47.8 \\
\hline
\end{tabular}

Enzyme treatment did not significantly affect the oenological parameters of the wine, with the exception of turbidity. The untreated wine was measured at a value of 43 NTU and further to enzyme treatment the value decreased to 19 NTU. When determining FI, the volumes filtered after $5 \mathrm{~min}$ were lower than $100 \mathrm{~mL}$ for the two experimental conditions. Only $25 \mathrm{~mL}$ of untreated wine and $35 \mathrm{~mL}$ of treated wine were collected. With these results the determination and interpretation of FI were not possible. The filtered volume after 5 min was too small to allow an evaluation of the filterability of these wines. In this case the determination of FI did not allow sufficient differentiation between the treated wine and the control even though the volume of treated wine was higher. A difference in the turbidity of the two wines was noted. FI was determined and turbidity measurements were carried out on numerous wines of diverse origins. The results observed are presented in Figure 2. 


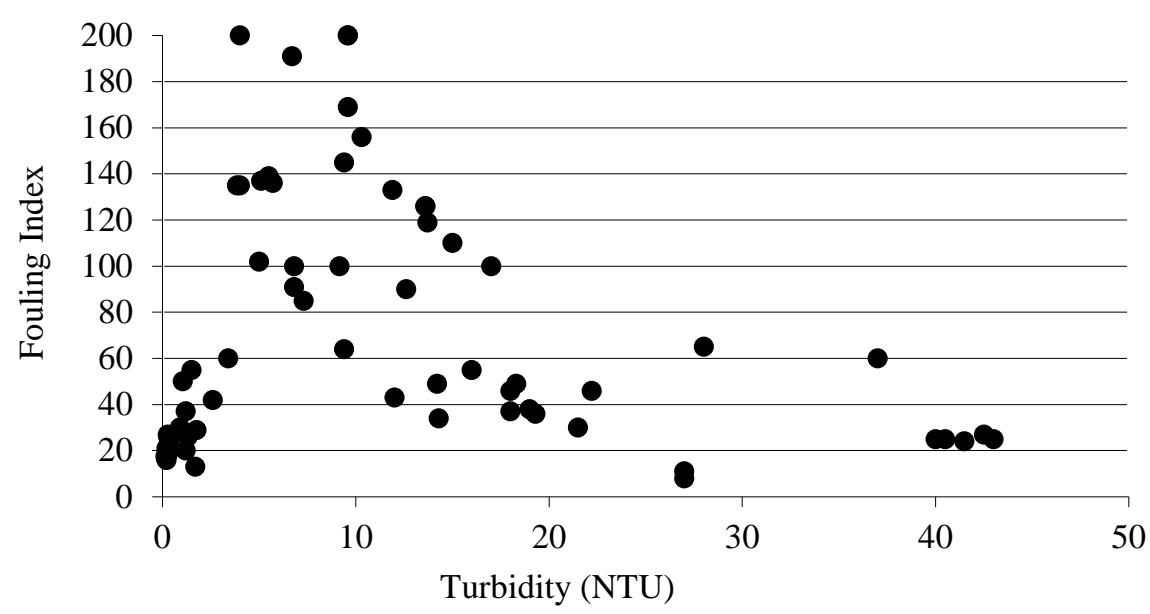

Figure 2. Fouling Index and turbidity of numerous wines

These data confirm that no correlation can be established between FI and the turbidity of wine. Moreover the results indicate that a wine of low turbidity $(<10 \mathrm{NTU})$ may have a high FI $(>40)$. The turbidity parameter cannot be related to the ability of a wine to filter efficiently. FI is a suitable indicator for wines with a very low propensity to fouling, which is the case of most of the wines ready for bottling. As the value of FI rises above 30, it becomes more and more difficult to interpret. Only an index value below 30 indicates that the wine can be filtered through a membrane. When the volume of filtered wine is less than $400 \mathrm{~mL}$ in $5 \mathrm{~min}$, FI is not measurable and is, therefore, not suitable as an indicator. In such a case, only the volume filtered $5 \mathrm{~min}$ is retained. FI and turbidity alone are not sufficient as indicators to qualify the filterability of a wide range of wines. Furthermore, the FI is realized on wines ready to be bottled. The above results are consistent with the findings in the work of Vernhet [27]. In this previous study no simple correlation could be found between wine turbidity, the composition in polysaccharides and polyphenols, and membrane fouling. Therefore, the turbidity of a wine is a characteristic which is not taken into account in assessing the filterability of that wine with the newly developed test. In order to better qualify unprocessed wines with a high propensity to fouling, a new Filterability Test (TF) has been developed. This new tool may be considered as a good basis on which to decide the best wine filtration strategy.

\subsection{Development of the new Test of Filterability (TF)}

TF measurements were made under the same experimental conditions as FI in order to facilitate use of the test. To meet this requirement, three measurement parameters were set at the beginning of the study: the use of a deadend filtration system, the use of the $25 \mathrm{~mm}$-diameter filter holder (Millipore), and the observance of a constant pressure of 2 bars. During the development of the TF, the aim was to determine the optimal conditions which would allow a clear differentiation of an untreated wine and a wine treated by an enzyme preparation.

\subsubsection{Membrane composition}

The first parameter studied was the impact of a variation of the material constituting the membrane. Six different membrane compositions $(0.6 \mu \mathrm{m}-0.7 \mu \mathrm{m}$ pore size, $25 \mathrm{~mm}$ in diameter) were tested under a constant pressure of 2 bars on control samples and on wines treated by enzymes (Table 4). It is important to note that the three wines tested had very different turbidity values.

Whatever the membrane used, the effect of enzyme treatment on filterability was positive for all wines tested. The filtered volume was significantly higher in every case for the enzyme-treated wines compared to the untreated wines (Wilcoxon test, $\alpha=5 \%, p$-value $=0.014$ ). Concerning the effect of membrane type on the filtered volume, no significant difference was observed (Kruskal\&Wallis test, $\alpha=5 \%$, p-value $=0.083$ ) . However, differences observed in the volume of wine collected after the filtration (at 5 minutes) show the influence of the different membrane compositions. The cellulose ester membrane filtered the greatest volume of wine B for the two experimental conditions (treated and untreated). The volumes collected with the RC and CA membranes were similar and the lowest filtered volume of wine B was obtained using the PTFE membrane. For wine C, CE and NC membranes showed equal performance. Finally, the test carried out on wine D showed that the largest volumes were obtained using a GF membrane.

All the membranes allowed the filtration of the various unprocessed wines while demonstrating the effectiveness of the enzyme treatment. The membranes were classified according to the filtered volume after 5 mins, from the most efficient to the least efficient composition: $\mathrm{GF}>(\mathrm{CE}=\mathrm{CN})>(\mathrm{RC}=\mathrm{CA})>\mathrm{PTFE}$. The results of 
this test show that the GF, CE, and CN membranes are interesting candidates for use in the development of the new test.

Table 4. Impact of membrane material on filtered volume of treated and untreated wines. (CE: cellulose esters; RC: regenerated cellulose; CA: cellulose acetate; CN: cellulose nitrate; GF: glass microfibre; PTFE: polytetrafluorethylene; TU: turbidity). $\mathrm{n}=2$

\begin{tabular}{|c|c|c|c|}
\hline & \multirow{2}{*}{$\begin{array}{c}\text { Membrane material } \\
\text { (Pore size } 0.6-0.7 \mu \mathrm{m} \text { ) }\end{array}$} & \multicolumn{2}{|c|}{ Filtered Volume at 5 minutes (mL) } \\
\hline & & Control & Treated wine \\
\hline \multirow{5}{*}{ Wine B } & & TU $=9.4 \mathrm{NTU}$ & TU $=7.3 \mathrm{NTU}$ \\
\hline & CE & $64.1 \pm 0.10$ & $85.3 \pm 4.65$ \\
\hline & $\mathrm{RC}$ & $51.2 \pm 0.55$ & $68.5 \pm 3.85$ \\
\hline & CA & $53.0 \pm 0.05$ & $68.4 \pm 0.40$ \\
\hline & PTFE & $49.8 \pm 0.45$ & $63.3 \pm 1.30$ \\
\hline \multirow{3}{*}{ Wine C } & & TU $=40$ NTU & TU $=18$ NTU \\
\hline & CE & $25.2 \pm 0.09$ & $37.7 \pm 2.54$ \\
\hline & $\mathrm{CN}$ & $24.4 \pm 0.22$ & $41.1 \pm 0.02$ \\
\hline \multirow{3}{*}{ Wine D } & & TU = 14 NTU & TU $=18 \mathrm{NTU}$ \\
\hline & $\mathrm{CE}$ & $34.3 \pm 4.12$ & $49.4 \pm 2.14$ \\
\hline & GF & $63.8 \pm 0.36$ & $68.1 \pm 1.77$ \\
\hline
\end{tabular}

\subsubsection{Evaluation of membrane material, pore size, and water flow-rate}

The variation of water flow rate is an important parameter to be taken into account in determining which membrane is to be used in the test of filterability. The membrane selected ought to have low heterogeneity in order to allow the standardization of the test. The heterogeneity of various membranes was evaluated in terms of two characteristics: composition and pore size (Figure 3).

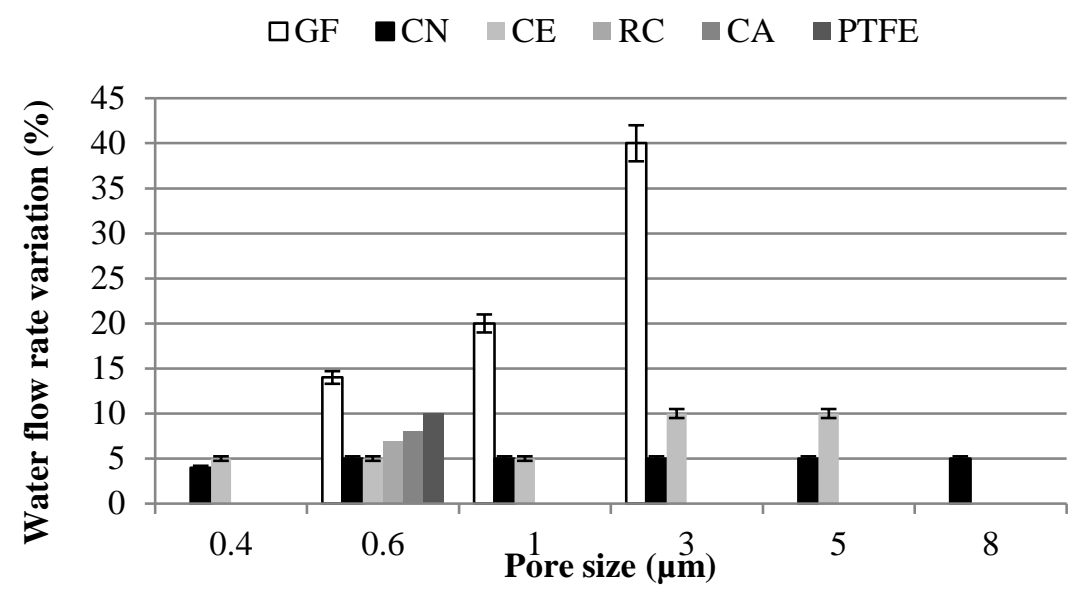

Figure 3. Variations of the water flow rate depending on the material and the pore diameter of the membrane. (CE: cellulose esters; RC: regenerated cellulose; CA: cellulose acetate; CN: cellulose nitrate; GF: glass microfibre; PTFE: polytetrafluorethylene). $n=5$.

Six different materials were tested for a $0.6 \mu \mathrm{m}$ pore size. In this test the CE and CN membranes proved to have the lowest variations in water flow rate $(<5 \%)$. Other materials exhibited considerable heterogeneity and it was noted that the largest variations were obtained with the GF membrane. All these tests illustrated the significant variations in water flow in the glass microfibre membranes (GF); these results reflect the high degree of heterogeneity of this filter medium. With the CE membrane, a water flow rate variation was obtained ranging from $5 \%$ for pore sizes $0.4,0.6$ and $1 \mu \mathrm{m}$ to $10 \%$ for pore sizes 3 and $5 \mu \mathrm{m}$. For all pore sizes tested the CN membrane produced small variations in the flow of water, generally less than or close to $5 \%$. At the end of the tests, the membrane with the lowest heterogeneity was selected to continue the development of the test of filterability. Thus the GF material was discarded because it has very poor repeatability in terms of determination of water flow rate. If the volumes filtered in 5 min were similar for $\mathrm{CN}$ and EC membranes, the $\mathrm{CN}$ membranes were esteemed to be the most suitable material to perform the test of filterability. Indeed, $\mathrm{CN}$ membranes are available in a wide range of pore sizes, and have the lowest heterogeneity in the determination of the water flow rate. 


\subsubsection{Evaluation of $\mathrm{CN}$ membrane (Sartorius) with different pore size}

After determining the most suitable membrane material it was necessary to specify which pore size was the most appropriate for the TF. The membrane must, in $5 \mathrm{~min}$, allow the filtration of a sufficient volume for a test to be carried out and must permit the differentiation between a wine that is untreated and one that has been subjected to enzyme treatment. Finally, it was also necessary to ensure that the membrane had the lowest degree of heterogeneity in order to produce a standardized TF. In order to meet these constraints, different membranes with pore sizes ranging from $0.2 \mu \mathrm{m}$ to $8 \mu \mathrm{m}$ were used to filter the volumes of treated and control wine A that were collected and measured after 5 min of filtration (Figure 4).

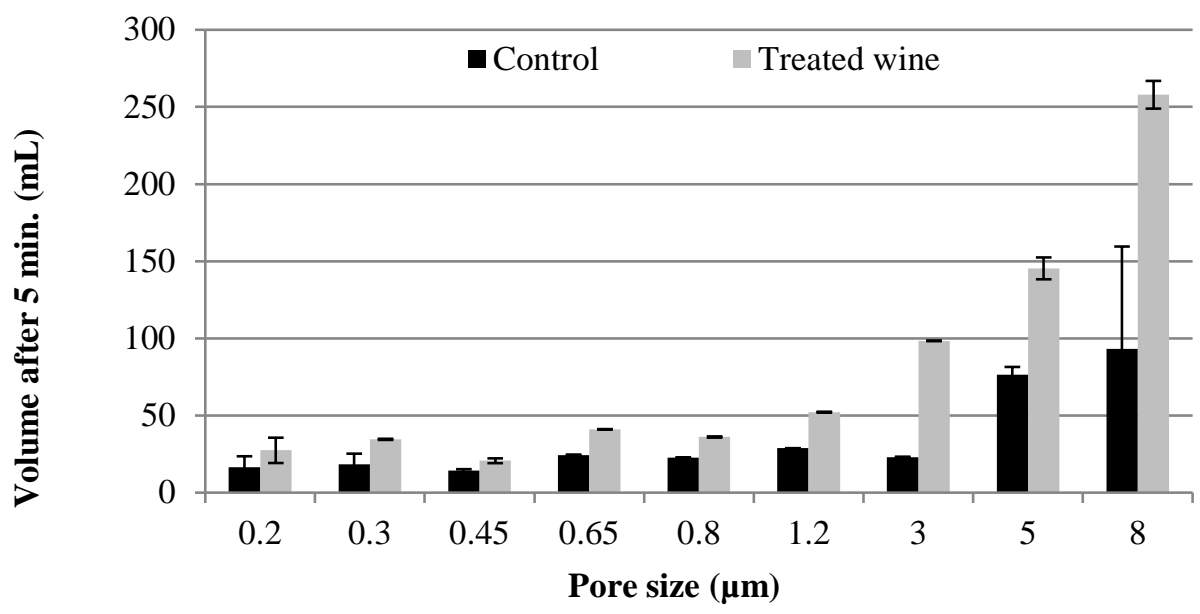

Figure 4. Effect of pore diameter on filtration of enzyme-treated and untreated (control) wine A. $\mathbf{n}=3$.

In all tests the volume of filtered wine collected after 5 min was significantly greater when the wine had been treated with enzymes (Wilcoxon test, $\alpha=5 \%$, p-value $=0.009$ ). At the end of the filtration, for both the treated and the untreated wines, the volumes obtained using membranes of pore sizes 0.2 to 0.8 microns were similar. The gradual increase in volumes obtained with membranes of the pore size $0.2 \mu \mathrm{m}-0.8 \mu \mathrm{m}$ is not important, whereas the volumes filtered through membranes with larger pore sizes were greater. The results show that the membrane with pore sizes between 1.2 and $8 \mu \mathrm{m}$ give the best results in terms of differentiation of enzyme-treated and untreated wines. In order to develop a test of filterability that is both interpretable and reliable the assessment of membrane heterogeneity is an essential pre-requisite. This evaluation of heterogeneity was carried out by measuring the water flow rate using ten membranes for each pore size under a constant 2 bars of pressure (Figure 5).

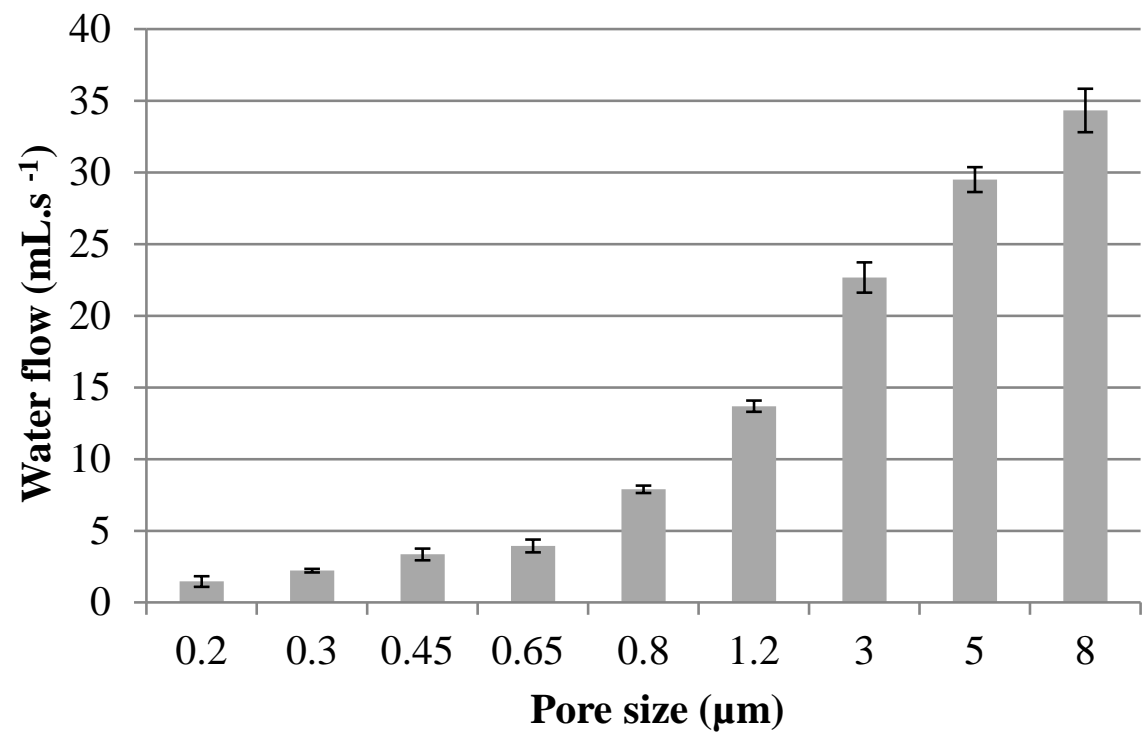

Figure 5. Water flow rate $\left(\mathrm{mL} . \mathrm{s}^{-1}\right)$ of $\mathrm{CN}$ membranes (Sartorius) for a wide range of pore sizes $(0.2 \mu \mathrm{m}-8$ $\mu \mathrm{m}), \mathbf{n}=10$. Different letters point to significant differences according to Steel-Dwass-Critchlow-Fligner test $(\mathbf{p}<0.05)$. 
The water flow rate is a function of membrane pore size, increasing as pore size becomes greater. The results obtained show that heterogeneity is specific to each pore sizes tested. The lowest heterogeneities, compared with standard deviation, were obtained with membranes of pore size $0.3,0.8$ and $1.2 \mu \mathrm{m}$. The choice of membrane for the test of filterability was based on two criteria: the ability to differentiate between enzyme-treated wines and untreated wines on the one hand and, on the other hand, the property of low heterogeneity, which is required for the standardization of the test. The CN membrane (Sartorius) with a pore size of $1.2 \mu \mathrm{m}$ was selected in view of these constraints and the experimental data collected. In order to ensure the homogeneity of the selected membrane with an alcohol solution such as wine, the flow rate with an ethanol-water solution at $10 \%$ was evaluated on ten membranes drawn from the same and from different boxes. The results and their repeatability are shown in Table 5.

Table 5. Water-alcohol solution (10\% (v/v)) flow-rate $\left.\left(\mathrm{mL}^{-1}\right)^{-1}\right)$ of $\mathrm{CN}$ membrane (Sartorius) $(25 \mathrm{~mm}$ diameter, $1.2 \mu \mathrm{m}$ pore size) under a constant pressure of 2 bars.

\begin{tabular}{ccc}
\hline Repeatability & Water-alcohol solution at $10 \% \mathrm{v} / \mathrm{v}$ & $\begin{array}{c}\text { Flow rate } \\
(\mathrm{mL} / \mathrm{s})\end{array}$ \\
\cline { 2 - 3 } test & $\begin{array}{c}\text { Time to filter } 400 \mathrm{~mL} \\
(\mathrm{~s})\end{array}$ & 12.11 \\
1 & 33.03 & 12.32 \\
2 & 32.47 & 12.16 \\
3 & 32.88 & 11.93 \\
4 & 33.53 & 12.40 \\
5 & 32.28 & 12.86 \\
6 & 31.09 & 12.20 \\
7 & 32.78 & 12.97 \\
8 & 30.84 & 12.24 \\
9 & 32.68 & 12.60 \\
\hline
\end{tabular}

The flow rate for a water-alcohol solution at $10 \%(\mathrm{v} / \mathrm{v})$ was determined for the Sartorius CN membrane with a mean pore size of $1.2 \mu \mathrm{m}$ diameter. The flow rate was estimated at $12.38 \pm 0.33 \mathrm{~mL} . \mathrm{s}^{-1}$ for a water-alcohol solution at $10 \%(\mathrm{v} / \mathrm{v})$. Variations in flow rate with the water-alcohol solution were small therefore acceptable. This test confirmed the choice of this membrane for use in the TF.

\subsection{Presentation of the new test of filterability (TF)}

\subsubsection{Experimental parameters}

The principle of the test of filterability is to measure the volume of wine that is filtered as function of time through a membrane (Sartorius, diameter $25 \mathrm{~mm}$, pore size $1.2 \mu \mathrm{m}$ ) in a filter holder (Millipore) of 25 mm diameter under a constant pressure of 2 bars. Before carrying out the test it is important to ensure the cleanliness of the apparatus. It is important to measure the flow of water through the membrane before performing the test in order to verify that the membrane is not defective. The correct flow rate of water has been estimated at $13.71 \pm 2.74$ $\mathrm{mL} . \mathrm{s}^{-1}$ (Table 5). The sample of wine $(750 \mathrm{~mL})$ to be tested must be at room temperature during 1 hour, and must always be racked above the sediment before being introduced into the stainless steel filtration vessel.

\subsubsection{Determination of the TF value}

During the test, the filtered volume was measured by weighing every 10 sec for 5 minutes. The graph of the filtered volume as a function of time was established by means of an automatic data collection system. The results shown in figure 6 were obtained with a red wine from Bordeaux ( $\mathrm{J}$ ) with an FI that was not measurable therefore not interpretable.

According to filtration law at constant pressure [29], four mechanisms may be involved in membrane fouling by particles: complete pore blocking, standard pore blocking, intermediate pore blocking, and cake filtration. Data collected during the test was linearized and interpreted according to standard pore blocking law (Figure 7) in which the data equation is:

$$
\mathrm{t} / \mathrm{v}=\mathrm{kt}+1 / \mathrm{Q}_{0}
$$

Parameters $\mathrm{t}$ and $\mathrm{V}$ represent respectively the time (min) and the filtered volume $(\mathrm{mL})$. The slope $\mathrm{k}$ reflects membrane fouling. 


$$
k=\frac{C_{V}}{S_{0} L_{p}}
$$

$C v$ represents the volume of retained particles per unit of filtrate volume; $L p$ is the length of the pores and $S_{0}$ the initial section of the pores.

The Test of Filterability score is determined by calculating $\mathrm{k}^{*} 10^{3}$ (in the example of figure 7, TF is 5.3 ). Using the equation obtained by linearization, the value of $\mathrm{Q}_{0}$ is known. $\mathrm{Q}_{0}\left(\mathrm{~mL} \mathrm{~min}^{-1}\right)$ represents the initial flow rate of the membrane. In theory $\mathrm{Q}_{0}$ is dependent only on the existence of a clean membrane and filtration system (membrane surface and pressure). Thus it is not taken into consideration in the calculation of the new Test of Filterability (TF) score. In all the experiments data linearization using standard pore blocking law was satisfactory. However, in order to detect any atypical wines governed by multiple filtration laws at constant pressure during the test, it was imperative to remain vigilant with respect to the linearization coefficient obtained.

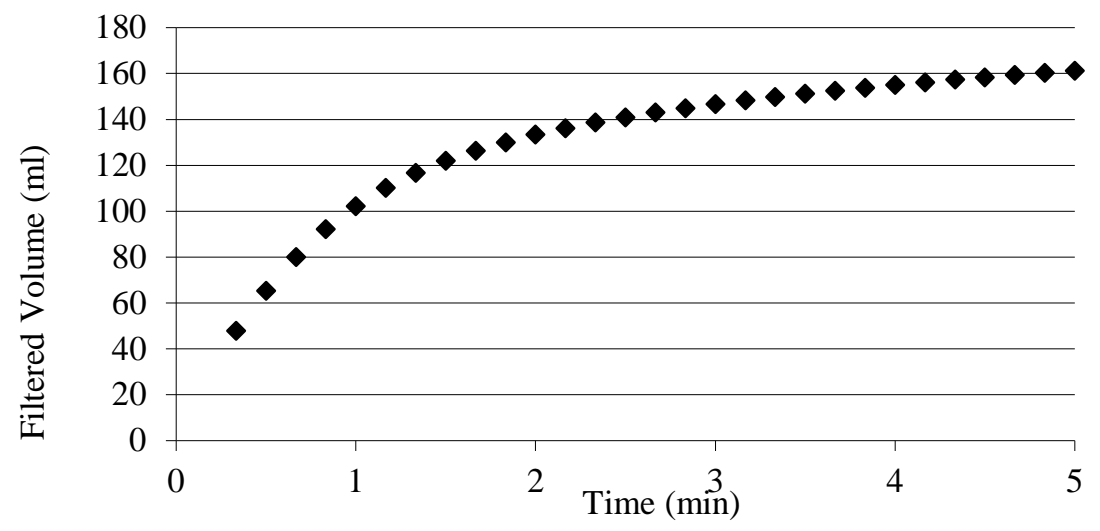

Figure 6. Volume $(\mathrm{mL})$ of filtered wine versus time $(\mathrm{min})$

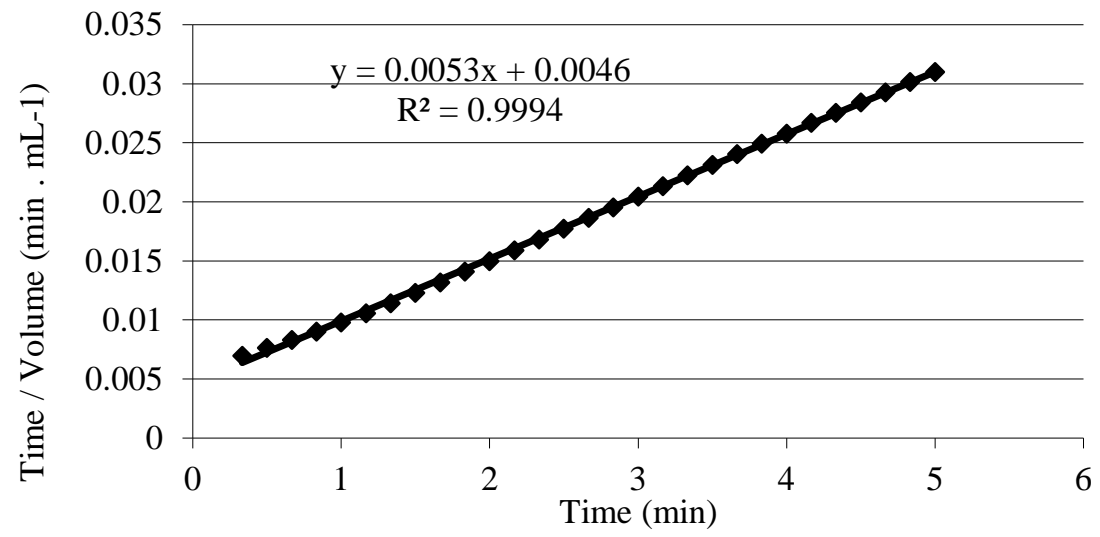

Figure 7. Linearization of data according to standard blocking law

\subsubsection{TF application}

The TF value is accurately determined and an increase in the score corresponds to a decrease in wine filterability. The lower the TF value, the greater is the filterability of the wine that is tested. The determination of the TF value is independent of the initial turbidity of a wine, TF being measurable whatever the turbidity (Table 6). The results shown clearly demonstrate the ability of TF to distinguish a wine treated by enzymes from an untreated wine, while turbidity is not an adequate parameter. All the results are statically different.

Table 6. Determination of Turbidity and TF determination for enzyme-treated (Treated) and untreated (Control) red wines.

\begin{tabular}{lcc|cc}
\hline Red Wines & \multicolumn{2}{c|}{ Turbidity (NTU) } & \multicolumn{2}{c}{ TF } \\
Origin & Control & Treated & Control & Treated \\
\hline Bordeaux (E) & $22 \pm 2$ & $10 \pm 1,4$ & $11.1 \pm 1,5$ & $3.0 \pm 0,2$ \\
Bordeaux (F) & $8.1 \pm 1,2$ & $2.9 \pm 0,4$ & $7.7 \pm 1,1$ & $4.4 \pm 0,3$ \\
Haut Medoc (G) & $7.9 \pm 1,1$ & $7.6 \pm 1,1$ & $3.5 \pm 0,5$ & $1.6 \pm 0,2$ \\
Haut Medoc (H) & $8.6 \pm 1,1$ & $8.7 \pm 1,1$ & $12.3 \pm 1,5$ & $8.6 \pm 1,1$ \\
Bordeaux (I) & $2.7 \pm 0,4$ & $3.5 \pm 0,5$ & $5.6 \pm 1$ & $1.3 \pm 0,2$ \\
\hline
\end{tabular}


In the course of this study a correspondence was established between the TF score and the filterability of a wine (Table 7). Filtered wines prior to bottling, characterized by a low propensity to fouling, generally have a TF score below 4. From these results it can be considered that enzyme-treated wine may be filtered directly for bottling. Wines requiring a pre-filtration stage typically have a TF value between 4 and 8 . When TF is greater than 8 the wine has a significant propensity to fouling. In this case a pretreatment such as fining is recommended. In all the cases studied enzyme treatment must be considered as an essential prerequisite to fining or prefiltration as enzymes are able to break down polysaccharides into smaller molecules, which has favourable effects on filtration efficiency.

Table 7. Filterability qualification of wines

\begin{tabular}{c|l}
\hline TF & \multicolumn{1}{c}{ Filterability qualification } \\
\hline 48 & $\begin{array}{l}\text { Wine with a substantial propensity to fouling, requiring pre-treatment (enzyme } \\
\text { treatment, fining, preliminary filtering) }\end{array}$ \\
$<<\mathrm{TF}<8$ & $\begin{array}{l}\text { Wine requiring pre-filtration (enzyme treatment, preliminary plates, clarifying, or } \\
\text { fine preliminary filtration ) } \\
\text { Wine filterable for bottling (sterilizing filtration plates or membrane filtration) }\end{array}$ \\
\hline
\end{tabular}

\section{Conclusions}

This study presents the development of a new tool for the evaluation of a wine's filterability. The Test of Filtrability (TF) has several advantages over existing tests. Firstly, the use of a single type of membrane the 25 mm-diameter, 1.2 micron nitrocellulose membrane manufactured by Sartorius. This facilitates the determination of the TF value since a single membrane is used independently of the initial turbidity of the wine. If a laboratory already measures the Filterability Index (FI), a simple change of membrane allows the determination of the TF score. The use of only one type of membrane from a specific manufacturer is an important element in the standardization of the TF, which may be carried out by any laboratory already equipped to measure the FI. The second advantage is the ability of TF to qualify the filterability of a wide range of wines: unprocessed wines, wines treated with a fining agent or an enzyme preparation, racked wines or wines ready for bottling. Thus, TF allows the determination of the filterability of wines which it is not possible to qualify by means of conventional indices currently used. Finally, the determination of the TF score is simple, rapid (5 min), and the calculation required to obtain the TF value is easy. Two areas of application can be considered for use and further development of the TF. The TF may initially be used to compare winemaking processes and their impact on the filterability of wines. In this way, a wine's filterability can be assessed following on from different oenological practices such as maceration or thermovinification processes. Furthermore, TF may be used to assess the influence of different treatment methods (enzyme addition, fining) or the use of additives (tannin, mannoproteins, gum) during the vinification process. Further research could be devoted to the establishment of a correlation between TF and the use of different filtration systems in oenology. Current work focusses on the correlation between the TF value and filter plates. The TF developed in this study is a decision aid for use in choosing a suitable filter medium as a function of a wine's filterability in order to optimize the filtration stages involved in winemaking. The optimization of filtration processes is a topic that is currently under scrutiny due to the environmental impact of filtration practices in winemaking. Finally, the possibility ought to be evaluated of extending the application of TF to other beverages such as fruit juice or beer.

\section{Acknowledgements}

The authors would like to acknowledge the support of the Conseil Régional d'Aquitaine, Novozymes and Lamothe-Abiet, France.

\section{References}

[1] Seabrook, A., Nazaris, B., \& Barthoux, J. 2020, Filtration: Factors around wine filterability. Australian and New Zealand Grapegrower and Winemaker, (674), 48.

[2] Ubeda J.F., Briones A.I. 1999. Microbiological quality control of filtered and non-filtered wines. Food Control, 10, 41-45. https://doi.org/10.1016/S0956-7135(98)00156-X

[3] Mangiamelli, M., Petegolli, D., \& Schneider, R. 2018, Reduce your filtration problems: A new enzyme formulation to prevent filter clogging. Australian and New Zealand Grapegrower and Winemaker, (651), 62. 
[4] Breniaux, M., Renault, P., Meunier, F., \& Ghidossi, R. 2019, Study of high power ultrasound for oak wood barrel regeneration: impact on wood properties and sanitation effect. Beverages, 5(1), 10. https://doi.org/10.3390/beverages5010010

[5] Breniaux, M., Zeng, L., Bayrounat, F., \& Ghidossi, R. (2019). Gas transfer management by membrane contactors in an oenological context: Influence of operating parameters and membrane materials. Separation and Purification Technology, 227, 115733. https://doi.org/10.1016/j.seppur.2019.115733

[6] Trevisan, M., Barthélémy, L., Ghidossi, R., \& Moulin, P. (2020). Silicon carbide (SiC) membranes in œnology: a laboratory-scale study. OENO One, 54(4), 719-732. https://doi.org/10.20870/oenoone.2020.54.4.3856

[7] El Rayess Y., Albasi C., Bacchin P., Taillandier P., Mietton-Peuchot M. and Devatine A. 2011. Cross-flow microfiltration applied to oenology: A review. J. Membrane Science, 385-386, 177-186. https://doi.org/10.1016/j.memsci.2011.08.008

[8] El Rayess, Y., Manon, Y., Jitariouk, N., Albasi, C., Peuchot, M. M., Devatine, A., \& Fillaudeau, L. 2016, Wine clarification with Rotating and Vibrating Filtration (RVF): Investigation of the impact of membrane material, wine composition and operating conditions. Journal of Membrane Science, 513, 47-57. https://doi.org/10.1016/j.memsci.2016.03.058

[9] Czekaj P., Lopez F., Güell C. 2001. Membrane fouling by turbidity constituents of beer and wine: characterization and prevention by means infrasonic pulsing. J. Food Engineering, 49, 25-36. https://doi.org/10.1016/S0260-8774(00)00181-3

[10] Ghidossi, R., Qiu, Y., Lacampagne, S., Mirabel, M., Renouf, V., \& Mietton-Peuchot, M. (2018). Oxygen desorption and oxygen transfer through oak staves and oak stave gaps: an innovative permeameter. OENO One, 52(1), 1-14. doi:10.20870/oeno-one.2017.51.4.1066

[11] Yammine, S., Rabagliato, R., Vitrac, X., Mietton-Peuchot, M., \& Ghidossi, R. 2019, The use of nanofiltration membranes for the fractionation of polyphenols from grape pomace extracts. OENO One, 53(1), 11-26. https://doi.org/10.20870/oeno-one.2018.52.4.1580

[12] Yammine, S., Rabagliato, R., Vitrac, X., Peuchot, M. M., \& Ghidossi, R.(2019), Selecting ultrafiltration membranes for fractionation of high added value compounds from grape pomace extracts. OENO One, 53(3), 487-497. https://doi.org/10.20870/oeno-one.2019.53.3.2343

[13] Nioi, C., Lisanti, M. T., Lacampagne, S., Noilet, P., Peuchot, M. M., \& Ghidossi, R. 2020,. Nanofiltration process as non-thermal alternative to thermovinification in Pinot noir winemaking. OENO One, 54(1), 3747. https://doi.org/10.20870/oeno-one.2020.54.1.2507

[14] Prodanov, M., Aznar, M., Cabellos, J. M., Vacas, V., López, F., Hernández, M. T., \& Estrella, M. I. 2019, Tangential-flow membrane clarification of Malvar (Vitis vinifera L.) wine: incidence on chemical composition and sensorial expression. https://doi.org/10.20870/oeno-one.2019.53.4.2480

[15] De La Garza F. and Boulton R. 1984. The modeling of wine filtrations. Am. J. Enol. Vitic., 35, 189-195.

[16] Gaillard M. 1976. Study on carbohydrate colloids and wine filtration. Mémoire Ecole Nationale d'Ingénieurs des Travaux Agricoles de Bordeaux.

[17] Serrano M. 1993. Methods for assessing the quality of clarifications. The clarification of musts and wines : filtration, centrifugation, flotation. JISVV, $n^{\circ}$ hors séries. p.30-34.

[18] Dubourdieu D., Villettaz J.C, Desplanques C. 1981. Enzymatic degradation of Botrytis glucan. Application to the improvement of wines from rotten grapes. Conn. Vigne et Vin, 15, 101-107.

[19] Villetaz J.C., Amado R., Neukom H. 1981. Carbohydrate Polymers, 1 (2), 101-105.

[20] Romat H., Reynou G. 2008. New filtration criteria for the oenological and economical control of filtration. Revue de Viticulture et d'œnologie de la Vallée du Rhône, 3, 71-76.

[21] Romat H. 2007. Coefficient of clogging: A new approach to wine filterability. Revue des œnologues, 123, 31-33.

[22] Romat H. 2012. Particulate and colloidal approach to filtration, Definition of an oenological index of filtration and practical applications, Revue des œnologues, 141, 45-47.

[23] Dubourdieu D., Desplanque C., Villettaz J.C., Ribereau-Gayon P. 1985. Investigations of an industrial $\beta$-dglucanase from Trichoderma harzianum Carbohydrate Research, 144 (2), 277-287. https://doi.org/10.1016/S0008-6215(00)90675-X

[24] Canal-Llaubère R.M., Reynou-Gravier G., Embeita A. 2010. Economic interest of a purified pectinase for extraction and settling: Synthesis of industrial trials in white and rosé. Revue des œnologues, 137, 12-14.

[25] Humbert-Goffard A., Saucier C., Moine-Ledoux V., Canal-Llaubères R., Dubourdieu D., Glories Y. 2004. An assay for glucanase activity in wine. Enzyme and Microbial Technology, 34, 537-543. https://doi.org/10.1016/j.enzmictec.2003.10.017

[26] OIV. 2007. Compendium of international methods of analysis of wines and musts. International Organisation de la Vigne et du Vin (OIV). Edition 2007. Volumes 1 and 2. 
[27] Descout J.J., Border J.L., Laurenty J., and Guimberteau G. 1976. Clogging phenomena during the filtration of wines on screen filters. Conn. Vigne et Vin, 10, 93-123. https://doi.org/10.20870/oeno-one.1976.10.1.1645

[28] Vernhet A., Cartalade D., Moutounet M. 2011 Contribution to the understanding of fouling build-up during microfiltration of wines. J. Membrane Science, 211, 357-370. https://doi.org/10.1016/S0376-7388(02)004325

[29] Tien C. and Ramarao B.V. 2011. Revisiting the laws of filtration: An assessment of their use in identifying particle retention mechanisms in filtration. J. Membrane Science, 383, 17-25.

(C) 2021 by the author(s). This work is licensed under a Creative Commons Attribution 4.0 International License (http://creativecommons.org/licenses/by/4.0/). Authors retain copyright of their work, with first publication rights granted to Tech Reviews Ltd. 